\title{
LETTER TO THE EDITOR \\ Public health implications of microbial food safety and foodborne diseases in developing countries
}

$\mathrm{F}$ ood is one of the most important transmission routes of diseases globally due to microbial contaminations (1). Global emergence and reemergence of foodborne pathogens have made microbiological safety and quality of food of public and health important $(1,2)$. Globally, more than 250 sources of foodborne diseases have been identified (3). Due to the increase of foodborne infectious diseases, several food quality regulations have been imposed in various countries. According to Grace, there is dearth of information regarding foodborne diseases in developing countries (4). Food contamination from microbial sources includes bacteria, protozoans, viruses, and fungi $(5,6)$. Consumption of food contaminated with foodborne pathogens and microbial by-products such as toxins could result in serious illnesses and economic loses (7). Currently, more than 2 million deaths occur every year in developing countries due to foodborne diseases, which are among more than 13 zoonoses implicated in over 2 billion illnesses worldwide (8). Those mostly affected are aged people, infants, children, and people with immunocompromised immune systems due to weakened immune system. It is therefore important that public health is taken into serious considerations in developing countries. In Africa, over 91 million people are affected according to recent report by the World Health Organization. It was also stated that 2.2 million children die of diarrhea every year in developing countries, while more than 600,000 children are reported to have died on yearly basis as a result of consumption of unsafe food in Southeast Asia (9). Among food implicated in foodborne diseases in developing countries are food from animal sources, fresh produce, and street-vended foods (4).

Over the years, safety and quality of food produced for human consumption in developing countries continue to increase because of foodborne disease outbreaks attributed to unsafe raw food, abused temperature, poor storage infrastructures, inadequate cooking, poor personal hygiene, improper handling methods, and crosscontamination of cooked food with uncooked raw food $(1,2,10,11)$. Food production in developing countries takes place mostly at home. Home serves as breeding ground for outbreak and spread of foodborne diseases. Personal hygiene of food handlers is, therefore, important to prevent outbreaks. In a recent study, it was observed that food handlers in Ghana, West Africa, lack knowledge of appropriate temperature for holding food and do not have adequate knowledge of sources of either contamination or cross-contamination (12). It was also observed in the study that water serves as most common route of transmission of foodborne pathogens. There are many factors influencing occurrence of foodborne diseases in developing countries, which when properly addressed can lead to reduction in occurrence of these diseases. Firstly, homes in developing countries serve as a key contributor to foodborne disease outbreaks due to the contamination of raw food with prepared food, lack of food safety awareness, poor personal hygiene, improper food handling, and preparation at home (13). Apart from contamination of food at home, other sources include farm, supply chain, consumers and food vendors, and lack of proper implementation of hazard analysis critical control point measures during food production (11). Some consumers store food at inappropriate temperatures, use contaminated cutting board, prepare food with unwashed hands, and store both raw and cooked food together, thereby causing cross-contamination $(14,15)$. It is, therefore, important that both food handlers and consumers are enlightened about the need for personal hygiene and food safety awareness as studies have shown that there is a strong correlation between food safety awareness and food safety attitude $(12,16,17)$.

In developing countries, most foodborne disease outbreaks are underreported or underestimated. For example, Nigeria is a country with over 170 million people. However, it was reported that only 90,000 cases of foodborne diseases occur annually. Australia is a developed country with just 24 million people equivalent to 1:7 when compared to Nigeria. Yet more than 5.2 million people are reported to have foodborne diseases annually in Australia despite the high standard of living, good water supply, proactive government initiatives, and measures on food safety. It could be deduced from this fact that at least 36 million people $(7 \times 5.2$ million $)$ are possibly affected every year in Nigeria. Hence, underestimation of incidence of foodborne diseases in developing countries will affect the kind of measures and strategies implemented to curb foodborne disease outbreaks.

In conclusion, economic and public health implications of foodborne diseases in developing countries cannot be overestimated. Therefore, collaborative effort between governments of developing countries, policymakers, researchers, 
and general public is imperative to reduce incidence of foodborne diseases. Use of rapid methods for detection of foodborne pathogens is required in developing countries. Human capacity development in state-of-art technologies and foodborne pathogen detection methods among researchers in developing countries in collaboration with researchers in developed countries is also encouraged for the prevention of transmission and awareness of foodborne diseases.

Olumide A. Odeyemi Springforth Scientific Resource Centre Ile-Ife, Osun State, Nigeria Email: oluodeyemi@gmail.com

\section{Conflict of interest and funding}

I declare no conflict of interests.

\section{References}

1. Odeyemi OA, Bamidele FA. Harnessing the potentials of predictive microbiology in microbial food safety and quality research in Nigeria. Future Science OA 2016; 2(1): FSO91-93.

2. Odeyemi OA, Sani NA. Antibiotic resistance and burden of foodborne diseases in developing countries. Future Science OA 2016; 2(1):FSO139.

3. Scallan E, Hoekstra RM, Mahon BE, Jones TF, Griffin PM. An assessment of the human health impact of seven leading foodborne pathogens in the United States using disability adjusted life years. Epidemiol Infect 2015; 143(13): 2795-804.

4. Grace D. Food safety in low and middle income countries. Int J Env Res Public Health 2015; 12(9): 10490-507.

5. Health NIo (2007). Understanding emerging and re-emerging infectious diseases. National Institutes of Health (US); Biological Sciences Curriculum Study. Bethesda (MD): National Institutes of Health (US). 1-13

6. Fineberg H, Wilson M. Emerging infectious diseases. IRGC Rep 2010.
7. Ben AS, Ainsley MO, Aamir MF, Greg MP, Anna ML. Microbial food safety risk assessment. In Compendium of methods for the microbiological examination of foods. In: eds. Downes F.P., Ito K, eds. American Public Health Association; 2013, pp. 1-369.

8. Kelly A, Osburn B, Salman M. Veterinary medicine's increasing role in global health. Lancet Glob Health 2014; 2(7): e379-80.

9. WHO (2015). WHO estimates of the global burden of foodborne diseases: foodborne disease burden epidemiology reference group 2007-2015. WHO Library Cataloguing-inPublication Data. 1-252.

10. Lund BM, O'Brien SJ. Public health measures: food safety in hospitals and other healthcare settings A2. In: Motarjemi Y, ed. Encyclopedia of food safety. Waltham, MA: Academic Press; 2014, pp. $140-8$.

11. Lamuka PO. Public health measures: challenges of developing countries in management of food safety A2. In: Motarjemi Y, ed. Encyclopedia of food safety. Waltham, MA: Academic Press; 2014, pp. 20-6.

12. Parry-Hanson Kunadu A, Ofosu DB, Aboagye E, Tano-Debrah K. Food safety knowledge, attitudes and self-reported practices of food handlers in institutional foodservice in Accra, Ghana. Food Control 2016; 69: 324-30.

13. Käferstein FK. Actions to reverse the upward curve of foodborne illness. Food Control 2003; 14(2): 101-9.

14. van Asselt ED, de Jong AEI, de Jonge R, Nauta MJ. Cross-contamination in the kitchen: estimation of transfer rates for cutting boards, hands and knives. J Appl Microbiol 2008; 105(5): 1392-401.

15. Azevedo I, Albano H, Silva J, Teixeira P. Food safety in the domestic environment. Food Control 2014; 37: 272-6.

16. Woh PY, Thong KL, Behnke JM, Lewis JW, Mohd Zain SN. Evaluation of basic knowledge on food safety and food handling practices amongst migrant food handlers in Peninsular Malaysia. Food Control 2016; 70: 64-73.

17. Baș M, Șafak Ersun A, Kıvanç G. The evaluation of food hygiene knowledge, attitudes, and practices of food handlers' in food businesses in Turkey. Food Control 2006; 17(4): 317-22. 